\title{
Clinical Pharmacology in Neonates: Small Size, Huge Variability
}

\author{
Karel Allegaert ${ }^{a, b}$ John N. van den Anker ${ }^{c-f}$ \\ ${ }^{a}$ Neonatal Intensive Care Unit, University Hospitals Leuven, and ${ }^{b}$ Department of Development and Regeneration, \\ KU Leuven, Leuven, Belgium; ' Division of Pediatric Clinical Pharmacology, Children's National Medical Center, and \\ ${ }^{\mathrm{d}}$ Departments of Pediatrics, Pharmacology and Physiology, George Washington University School of Medicine and

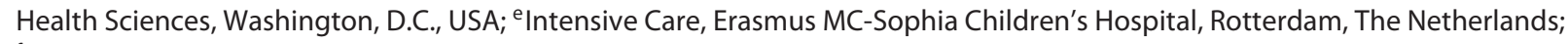 \\ ${ }^{f}$ Department of Pediatric Pharmacology, University Children's Hospital, Basel, Switzerland
}

\section{Key Words}

Neonatal pharmacotherapy · Off-label compounds .

Suboptimal care

\begin{abstract}
Drug therapy is a powerful tool for improving neonatal outcome. Despite this, neonatologists still routinely prescribe off-label compounds developed for adults and extrapolate doses from those used for children or adults. Knowledge integration through pharmacokinetic modeling is a method that could improve the current situation. Such predictive models may convert neonatal pharmacotherapy from explorative to confirmatory. This can be illustrated by research projects related to the prediction of neonatal renal clearance and neonatal glucuronidation. This type of model will also improve the current knowledge of neonatal (patho)physiology. In the meanwhile, the fields of clinical pharmacology (e.g. pharmacokinetic/pharmacodynamic modeling and pharmacogenetics) and neonatology (e.g. whole-body cooling and the lower limit of viability) have both matured, resulting in new research topics. However, in order for the modeling and the newly emerging topics to become effective tools, they need to be tailored to the specific characteristics of neonates. Consequently, the field of neonatal pharmacotherapy needs dedicated neonatologists who continue
\end{abstract}

to raise the awareness that off-label practices, eminencebased dosing regimens and the absence of neonatal drug formulations all reflect suboptimal care.

C 2014 S. Karger AG, Basel

\section{Introduction}

When a compound is prescribed, the aim is to attain targeted effects (e.g. bactericidal, analgesic or normalization of blood pressure), preferably without disproportional side effects (e.g. drug toxicity, hypotension or tachycardia). Clinical pharmacology aims to estimate such side effects at the level of the population or, preferably, the individual [1, 2]. Pharmacokinetics (PK) describes the relationship between a concentration in a specific compartment (e.g. plasma, cerebrospinal fluid and bronchial epithelial lining fluid) and time (concentration/time, 'what the body does to the drug'). Pharmacodynamics (PD) describes the relationship between a concentration in a specific compartment and (adverse) effects (concentration/effect, 'what the drug does to the body'). The concepts of clinical pharmacology obviously also apply to neonates, but their physiological characteristics require a tailored approach $[3,4]$.

Covariate analysis is an important tool for translating information on the newborn population in general to each

\section{KARGER}

E-Mail karger@karger.com

www.karger.com/neo
(C) 2014 S. Karger AG, Basel

1661-7800/14/1054-0344\$39.50/0
Karel Allegaert, MD, PhD

Neonatal Intensive Care Unit

University Hospitals Leuven

Herestraat 49, BE-3000 Leuven (Belgium)

E-Mail karel.allegaert@uzleuven.be 
neonate in need of individualized pharmacotherapy $[3,4]$. Covariates are specific characteristics that explain in part the inter- and intra-individual PK/PD variability. The most obvious covariates in neonates relate to growth and development, reflected and quantified by birth weight, current weight or age, i.e. postnatal, gestational or postmenstrual age. There is already at least one order of variability in weight $(<0.5$ up to $5 \mathrm{~kg})$ while both the height velocity rate $(10-20 \mathrm{~cm} /$ year $)$ and the increase in body weight (50\% increase in the first 6 weeks) reflect the dynamics of a rapidly evolving biological system in perinatal life. The maturation-related variability is further aggravated by interfering disease characteristics (e.g. renal failure, sepsis and growth restriction) or treatment modalities (e.g. co-medication, extracorporeal membrane oxygenation and whole-body cooling). Moreover, maturation (e.g. receptor expression, receptor activity, cellular metabolism and enzyme activity) interrelates with growth. Some tissues may be more sensitive to specific compounds in early life, irrespective of a given concentration or exposure, whereas others will be less sensitive. This will affect population-specific PD. Beyond clinical pharmacology, the most crucial characteristic of perinatology is, in fact that despite the limited size, there is extensive variability, related to rapidly evolving physiology $[3,4]$.

Drug therapy is a powerful tool for improving neonatal outcome. Despite this, neonatologists still routinely prescribe off-label compounds and extrapolate doses and indications from those used for children or adults, without fully considering perinatal physiology. PK/PD modeling is an emerging tool that can improve the current situation by its capacity to convert neonatal pharmacotherapy from explorative to confirmatory. This can be illustrated by modeling projects on neonatal renal clearance and neonatal glucuronidation. Such models also improve the knowledge of neonatal (patho)physiology. This is illustrated by recent data on maturational differences in renal versus hepatic elimination routes and drug-drug interactions. Finally, both clinical pharmacology [e.g. PK/PD modeling and pharmacogenetics (PG)] and neonatology (wholebody cooling and the lower limit of viability) have matured, resulting in new topics for research.

\section{Modeling as a Structured Approach to Improve Knowledge of Pharmacotherapy}

A powerful tool to improve neonatal pharmacotherapy and facilitate clinical studies is knowledge integration through PK modeling. PK modeling is through

Clinical Pharmacology in Neonates mechanism-based PK or physiology-based (PB)-PK [47]. Mechanism-based models apply a bottom-up 'from compound to model' concept: based on drug-specific observations, covariates are described, resulting in mechanism-based models. PB-PK applies a top-down 'from physiology to clinical observations' concept: based on available data on neonatal physiology (e.g. weight, cardiac output and renal function), a PB-PK model can be developed [4-7]. These models hold promise for predicting the PK/PD of compounds if the normal clearance routes are known. Such approaches were recently reported for drug-related clearance through either glomerular filtration rate $[8,9]$ or glucuronidation in early life [10].

For the renal model, a covariate model characterizing developmental changes in the clearance of amikacin in neonates was developed based on birth weight, postnatal age and ibuprofen exposure [8]. Assuming that such a model contains physiological information on glomerular filtration rate ontogeny, the amikacin covariate model was subsequently applied to datasets of other aminoglycosides and glycopeptides (i.e. netilmicin, gentamicin, tobramycin and vancomycin). It was hereby documented that the descriptive and predictive properties of the models developed using the amikacin covariate model were good, and were fairly similar to the independent reference models, with similar clearance values being obtained with both approaches [9]. This study hereby confirmed that neonatal covariate models may contain physiological information since information derived from one drug can be used to describe other drugs. This approach may be used to optimize sparse data analysis and to derive individualized dosing algorithms for drugs in newborns. Such dosing algorithms obviously need prospective validation, since Zhao et al. [11] illustrated the potential hazards related to the transfer of published vancomycin models to different clinical settings. The predictive performance of 6 earlier published models was evaluated and differences were found in the predictive performance of models for vancomycin $\mathrm{PK}$ in neonates. This means, in essence, that a model described in a cohort in a given hospital does not automatically predict data for another cohort in another hospital. In this specific example, it was concluded that dosage individualization of vancomycin in neonates should consider not only clinical characteristics but also the methods used to measure serum creatinine and vancomycin [11]. A similar effort has been reported for glucuronidation, based on morphine glucuronidation in neonates, subsequently extrapolated to zidovudine glucuronidation [10]. 


\section{Developmental Pharmacology Reflects Developmental Physiology}

The different routes of elimination do not mature simultaneously but all have their process-specific maturational pattern (e.g. glomerular filtration vs. renal tubular excretion, CYP2D6 vs. CYP3A4/5 or renal vs. hepatic clearance) [1-4]. This implies that it is important to integrate the ontogeny-related knowledge of the different elimination pathways to be able to predict compoundspecific, phenotypic in vivo observations in neonates. There is no such thing as a neonatal kidney or liver, but only newborns in need of improved pharmacotherapy. This also means that specific settings (renal failure, hepatic failure or drug-drug interactions) described in children or adults need to be interpreted cautiously in the newborn by taking the available knowledge on developmental physiology into account.

Metabolites like O-desmethyl tramadol (analgesia), morphine glucuronides (analgosedation) or 1-hydroxymidazolam (sedation) may accumulate in neonates not because the metabolic clearance is already very effective, but because the subsequent renal elimination of the metabolites is even less effective [12]. The same holds true for propylene glycol, an alcohol commonly used as an excipient in drug formulations. In adults, primary renal elimination accounts for $45 \%$ and hepatic metabolic clearance through alcohol dehydrogenase for $55 \%$. In neonates, the contribution of primary renal elimination was much more limited (15-25\%) while the major route for clearance was through hepatic metabolism [13]. The phenotypic result is that propylene glycol clearance in neonates is low and depends strongly on the hepatic metabolic capacity. This likely explains the side effects described with Kaletra syrup [1 ml contains $80 \mathrm{mg}$ of lopinavir co-formulated with $20 \mathrm{mg}$ of ritonavir + excipients, including $356.3 \mathrm{mg}$ of ethanol $(42.4 \% \mathrm{v} / \mathrm{v})$ and 152.7 $\mathrm{mg}$ of propylene glycol $(15.3 \% \mathrm{w} / \mathrm{v})]$ administration in neonates. This formulation contains propylene glycol and ethanol and simultaneous exposure results in accumulation through competition for hepatic clearance. In contrast, the associated renal failure, commonly described as a risk factor for propylene glycol accumulation in adults, is likely of limited relevance in neonates [13].

Similar to excipient-excipient interactions, drug-drug interactions are only anecdotally explored in neonates. Salem et al. [14] recently reported a 'PBPK-model' to predict drug-drug interactions throughout pediatric life. For a theoretical compound metabolized $50 \%$ by CYP2D6 and CYP3A4 pathways at birth, co-administration of ke- toconazole $(3 \mathrm{mg} / \mathrm{kg}$, CYP3A4 inhibitor) resulted in a 1.65 -fold difference between inhibited versus uninhibited concentration time profiles compared to 2.4-fold in 1 -year-olds and 3.2-fold in adults. Obviously, neonates could be more sensitive to such PD interactions than adults.

\section{Emerging Clinical Research Topics}

\section{Pharmacogenetics}

The idea of individualized clinical pharmacology through integration of $P G$ reflects the fact that specific (side) effects are not merely randomly distributed. PG explores interindividual differences in drug response related to genetic variations, i.e. polymorphisms. Genetic variations can affect drug disposition through modifying receptor sensitivity or differences in drug metabolism. This obviously holds promise for the tailoring of perinatal clinical pharmacology beyond the usual covariates like age, weight or disease characteristics [15]. There are illustrations on the integration of PG and age-related maturation (i.e. ontogeny) to improve the prediction of phenotypic drug metabolism [cytochrome P450 (CYP) C219, CYP 2D6 or N-acetyl transferase (NAT) 2] [1618]. Based on in vivo observations of pantoprazole (CYP 2C19), tramadol (CYP2D6) and isoniazide metabolic clearance, respectively, an age-related impact of specific polymorphisms was documented. Obviously, this is limited to isoenzymes that are sufficiently active already in early life. This likely explains the absence of a link between CYP2C8 and CYP2C9 polymorphisms and the response to ibuprofen to induce closure of the patent ductus arteriosus [19].

More importantly, PG studies in perinatal life should go beyond confirmation of associations described in adults and explore the impact of PG as a covariate limited to perinatal life during which the genotype-phenotype concordance still exists $[15,16]$. This includes issues like fetal malformations, breastfeeding or neonatal clinical syndromes. A recent illustration of such an approach is the impact of polymorphisms on the severity of neonatal abstinence syndrome following maternal opioid intake [20]. While the median length of stay for term neonates was 35 days, specific catechol-O-methyltransferase (COMT, 158A $>\mathrm{G}$ ) and $\mu$-opioid receptor (OPRM1, $118 \mathrm{~A}>\mathrm{G}$ ) polymorphisms were associated with a median reduction of 10.8 and 8.5 days, respectively. Interestingly, breastfeeding itself (on univariate analysis) resulted in a reduction of 18 days [20]. 
This confirms findings reported by Sistonen et al. [21] on the links between genetic polymorphisms in mothers and their infants and the variation in response to standard doses of maternal opioids (e.g. codeine). The authors hereby explored the associations between polymorphisms in CYP2D6, UDP-glucuronosyltransferase 2B7 (UGT2B7), P-glycoprotein (ABCB1), OPRM1, COMT genes and central nervous depression in 111 infants during breast-feeding. A model combining specific maternal-risk genotypic polymorphisms (CYP2D6 and $\mathrm{ABCB} 1$ ) was associated with central nervous depression in both the mothers (OR 2.74) and their offspring (OR 2.68) [21].

\section{Thermopharmacology in Neonates}

Therapeutic hypothermia is an effective and valid treatment in term newborns following perinatal asphyxia. This relates to the effect of hypothermia on cerebral metabolism, but hypothermia itself also affects physiological functions such as circulation and metabolic activity [22]. Consequently, this modality may affect physicochemical properties and the PK/PD of the drugs. These aspects are covered by thermopharmacology, a term recently introduced into neonatal pharmacology by Van den Broek et al. [23, 24]. However, in current practice, hypothermia is an additional intervention in neonates with peripartal asphyxia. Based on currently available in vivo observations, it seems that primary renal elimination of aminoglycosides, for example, is not further reduced when hypothermia is applied and that asphyxia itself already reduces clearance [25]. In contrast, metabolic clearance seems to be reduced as illustrated for lidocaine (dependent on hepatic blood flow), morphine (glucuronidation) or phenobarbital (dependent on hepatic drug metabolism) [23, 24]. Besides PK effects, there are also some PD-related effects since the transition rate from a continuous normal voltage to a discontinuous normal voltage aEEG background level seems to be reduced in hypothermic asphyxiated newborns in comparison to in a normothermic setting. Similarly, the growth of bacteria also depends on temperature, and hypothermia may affect the PK/PD relation of antibiotics in neonates.

\section{Clinical Pharmacology at the Limit of Viability}

The overall outcome - including both mortality and (co)morbidity - in extreme preterm neonates strongly depends on their age at birth, weight at birth and gender. Despite this, the pharmacological tools commonly used at the limit of viability when compared to less-immature neonates are not fundamentally different, the dosing is commonly extrapolated from the neonatal practices for less-immature neonates, and none of these practices takes gender-specific modalities into account. Perhaps we should consider additional subpopulations within neonatal intensive care. The post hoc analysis on the age-dependent magnitude and direction of neurodevelopmental outcome following prophylactic thyroid hormone supplementation may serve as an illustration here [26]. A gestational age-dependent effect of thyroxine on neurodevelopmental outcome was found in post hoc subgroup analyses up until the age of 10 years. Thyroxine treatment was associated with improved mental, motor and neurological outcomes in infants $<28$ weeks' gestation, but with worse mental and neurological outcomes in infants of $\geq 29$ weeks' gestation [26].

Drug therapy is a powerful tool for improving neonatal outcome, but may also result in side effects. Adverse drug reactions in critically ill newborns may cause harm that further increases morbidity or mortality. However, differentiation of adverse drug reactions from reactions related to immaturity or disease (e.g. renal or hepatic dysfunction) is difficult, while we take it for granted that the overall rate of (co)morbidity in extremely preterm neonates at the limit of viability is high [27]. Similar to PG, pharmacovigilance also needs to be tailored to the specific characteristics of newborns. The decades that were needed to document appropriate oxygen targets for preterm infants, or more recently, the dexamethasone observations or the trends towards less-invasive ventilation strategies should at least raise awareness that any treatment intended to improve outcome in neonates may, in itself, have unanticipated (long-term outcome) side effects [28-30]. In a recent systematic review on perinatal interventions, Teune et al. [31] documented that unfortunately only $40 / 249$ (16\%) randomized controlled trials followed neonates after discharge from the hospital, without any improvement in consecutive time intervals (15\% before 1990, 15\% between 1990 and 2000 and 19\% since 2001).

\section{Concluding Remarks}

Effective pharmacotherapy depends on predictable PK and PD. In both these aspects, newborns can differ significantly from children or adults. Extrapolation of safety and efficacy can be made more reliable when methods developed in other fields of clinical pharmacology can be integrated into neonatal clinical research and care. These 
methods include modeling, PG and pharmacovigilance, but they will need to be tailored to the needs and characteristics of neonates to turn them into effective tools. Consequently, the field of neonatal pharmacotherapy needs dedicated neonatologists who continue to raise the awareness that off-label practices, eminence-based dosing regimens and the absence of neonatal drug formulations continue to reflect suboptimal care.

\section{Acknowledgements}

Karel Allegaert is supported by the Fund for Scientific Research, Flanders (Clinical Fellowship 1700314N Fundamental Clinical Investigatorship) and by an IWT-SBO project (130033). Johannes van den Anker is supported in part by NIH grants (R01HD060543, K24DA027992, R01HD048689 and U54HD071601) and FP7 grants TINN (223614), TINN2 (260908) and NEUROSIS (223060).

\section{Disclosure Statement}

No issues to be disclosed.

\section{References}

-1 Kearns GL, Abdel-Rahman SM, Alander SW, Blowey DL, Leeder JS, Kauffman RE: Developmental pharmacology - drug disposition, action, and therapy in infants and children. $\mathrm{N}$ Engl J Med 2003;349:1157-1167.

-2 Allegaert K, Verbesselt R, Naulaers G, van den Anker JN, Rayyan M, Debeer A, de Hoon J: Developmental pharmacology: neonates are not just small adults. Acta Clin Belg 2008;63:16-24.

- 3 De Cock RF, Piana C, Krekels EH, Danhof M, Allegaert K, Knibbe CA: The role of population PK-PD modelling in paediatric clinical research. Eur J Clin Pharmacol 2011;67(suppl 1):5-16.

- 4 Smits A, Kulo A, de Hoon JN, Allegaert K: Pharmacokinetics of drugs in neonates: pattern recognition beyond compound specific observations. Curr Pharm Des 2012;18:3119-3146.

5 Barrett JS, Della Casa Alberighi O, Läer S, Meibohm B: Physiologically based pharmacokinetic (PBPK) modeling in children. Clin Pharmacol Ther 2012;92:40-49.

6 Strougo A, Eising T, Yassen A, Willmann S, Danhof M, Freijer J: First dose in children: physiological insights into pharmacokinetic scaling approaches and their implications in paediatric drug development. J Pharmacokinet Pharmacodyn 2012;39:195-203.

7 Knibbe CA, Danhof M: Individualized dosing regimens in children based on population PKPD modelling: are we ready for it? Int J Pharm 2011;415:9-14.

8 De Cock RF, Allegaert K, Schreuder MF, Sherwin CM, de Hoog M, van den Anker JN, Danhof M, Knibbe CA: Maturation of the glomerular filtration rate in neonates, as reflected by amikacin clearance. Clin Pharmacokinet 2012;51:105-117.

$\checkmark 9$ De Cock RF, Allegaert K, Sherwin CM, Nielsen EI, de Hoog M, van den Anker JN, Danhof M, Knibbe CA: A neonatal amikacin covariate model can be used to predict ontogeny of other drugs eliminated through glomerular filtration in neonates. Pharm Res 2014;31:754-767.
10 Krekels EH, Neely M, Panoilia E, Tibboel D, Capparelli E, Danhof M, Mirochnick M, Knibbe CA: From pediatric covariate model to semiphysiological function for maturation. Part I. Extrapolation of a covariate model from morphine to zidovudine. CPT Pharmacometrics Syst Pharmacol 2012;1:e9.

11 Zhao W, Kaguelidou F, Biran V, Zhang D, Allegaert K, Capparelli EV, Holford N, Kimura T, Lo YL, Peris JE, Thomson A, van den Anker JN, Fakhoury M, Jacqz-Aigrain E: External evaluation of population pharmacokinetic models of vancomycin in neonates: the transferability of published models to different clinical settings. Br J Clin Pharmacol 2013;75: 1068-1080.

12 Allegaert K, Rochette A, Veyckemans F: Developmental pharmacology of tramadol during infancy: ontogeny, pharmacogenetics and elimination clearance. Paediatr Anaesth 2011; 21:266-273.

13 De Cock RF, Allegaert K, Vanhaesebrouck S, de Hoon J, Verbesselt R, Danhof M, Knibbe CA: Low but inducible contribution of renal elimination to clearance of propylene glycol in preterm and term neonates. Ther Drug Monit 2013, Epub ahead of print.

14 Salem F, Johnson TN, Barter ZE, Leeder JS, Rostami-Hodjegan A: Age-related changes in fractional elimination pathways for drugs: assessing the impact of variable ontogeny on metabolic drug-drug interactions. J Clin Pharmacol 2013;53:857-865.

15 Leeder JS, Kearns GL, Spielberg SP, van den Anker J: Understanding the relative roles of pharmacogenetics and ontogeny in pediatric drug development and regulatory science. J Clin Pharmacol 2010;50:1377-1387.

6 Leeder JS, Kearns G: Interpreting pharmacogenetic data in the developing neonate: the challenge of hitting a moving target. Clin Pharm Ther 2012;92:434-436.
7 Allegaert K, van den Anker JN, de Hoon JN, van Schaik RH, Debeer A, Tibboel D, Naulaers $\mathrm{G}$, Anderson BJ: Covariates of tramadol disposition in the first months of life. Br J Anaesth 2008;100:525-532.

18 Zhu R, Kiser JJ, Seifart HI, Werely CJ, Mitchell CD, D'Argenio DZ, Fletcher CV: The pharmacogenetics of NAT2 enzyme maturation in perinatally HIV exposed infants receiving isoniazid. J Clin Pharmacol 2012;52: 511-519.

19 Durrmeyer X, Hovhannisyan S, Médard Y, Jacqz-Aigrain E, Decobert F, Barre J, Alberti C, Aujard Y, Danan C, Baud O: Are cytochrome P450 CYP2C8 and CYP2C9 polymorphisms associated with ibuprofen response in very preterm infants? PLoS One 2010;5:e12329.

20 Wachman EM, Hayes MJ, Brown MS, Paul J, Harvey-Wilkes K, Terrin N, Huggins GS, Aranda JV, Davis JM: Association of OPRM1 and COMT single-nucleotide polymorphisms with hospital length of stay and treatment of neonatal abstinence syndrome. JAMA 2013;309:1821-1827.

21 Sistonen J, Madadi P, Ross CJ, Yazdanpanah M, Lee JW, Landsmeer ML, Nauta M, Carleton BC, Koren G, Hayden MR: Prediction of codeine toxicity in infants and their mothers using a novel combination of maternal genetic markers. Clin Pharmacol Ther 2012;91: 692-699.

22 Wildschut ED, van Saet A, Pokorna P, Ahsman MJ, van den Anker JN, Tibboel D: The impact of extracorporeal life support and hypothermia on drug disposition in critically ill infants and children. Pediatr Clin North Am 2012;59:1183-1204.

23 Van den Broek MP, Groenendaal F, Toet MC, van Straaten HL, van Hasselt JG, Huitema AD, de Vries LS, Egberts AC, Rademaker CM: Pharmacokinetics and clinical efficacy of phenobarbital in asphyxiated newborns treated with hypothermia: a thermopharmacological approach. Clin Pharmacokinet 2012;51:671-679. 
24 Van den Broek MP, Rademaker CM, van Straaten HL, Huitema AD, Toet MC, de Vries LS, Egberts AC, Groenendaal F: Anticonvulsant treatment of asphyxiated newborns under hypothermia with lidocaine: efficacy, safety and dosing. Arch Dis Child Fetal Neonatal Ed 2013;98:F341-F345.

25 Liu X, Borooah M, Stone J, Chakkarapani E, Thoresen M: Serum gentamicin concentrations in encephalopathic infants are not affected by therapeutic hypothermia. Pediatrics 2009; 124:310-315.
26 Van Wassenaer AG, Kok JH: Trials with thyroid hormone in preterm infants: clinical and neurodevelopmental effects. Semin Perinatol 2008:32:426-430.

$27 \mathrm{Du}$ W, Tutag Lehr V, Lieh-Lai M, Koo W, Ward RM, Rieder MJ, van den Anker JN, Reeves JH, Mathew M, Lulic-Botica M, Aranda JV: An algorithm to detect adverse drug reactions in the neonatal intensive care unit: a new approach. J Clin Pharmacol 2013;53: 87-95.

28 Shinwell ES: Optimization of airway medications in the infant. Neonatology 2013;103: 331-334.

29 Stenson BJ: Oxygen targets for preterm infants. Neonatology 2013;103:341-345.
30 Sweet DG, Carnielli V, Greisen G, Hallman M, Ozek E, Plavka R, Saugstad OD, Simeoni U, Speer CP, Vento M, Halliday HL: European consensus guidelines on the management of neonatal respiratory distress syndrome in preterm infants - 2013 update. Neonatology 2013;103:353-368.

31 Teune MJ, van Wassenaer AG, Malin GL, Asztalos E, Alfirevic Z, Mol BW, Opmeer BC: Long-term child follow-up after large obstetric randomised controlled trials for the evaluation of perinatal interventions: a systematic review of the literature. BJOG 2013;120:1522. 